\title{
Mathematical Modeling and Analysis of Drill String Longitudinal Vibration with Lateral Inertia Effect
}

\author{
Jialin Tian, ${ }^{1,2}$ Chunming Wu, ${ }^{1}$ Lin Yang, ${ }^{1}$ Zhi Yang, ${ }^{1}$ Gang Liu, ${ }^{1}$ and Changfu Yuan \\ ${ }^{1}$ School of Mechatronic Engineering, Southwest Petroleum University, Chengdu 610500, China \\ ${ }^{2}$ School of Mechanical Engineering, Southwest Jiaotong University, Chengdu 610031, China \\ Correspondence should be addressed to Jialin Tian; tianjialin001@gmail.com and Chunming Wu; 1769752908@qq.com
}

Received 16 July 2015; Revised 8 January 2016; Accepted 17 January 2016

Academic Editor: Sergio De Rosa

Copyright (c) 2016 Jialin Tian et al. This is an open access article distributed under the Creative Commons Attribution License, which permits unrestricted use, distribution, and reproduction in any medium, provided the original work is properly cited.

\begin{abstract}
Comparative analysis whether considering the lateral inertia or not, aiming at the longitudinal vibration of the drill string in drilling progress, is proposed. In the light of the actual condition, the mechanical model of the drill string about vibration is established on the basis of the theoretical analysis. Longitudinal vibration equation of the drill string is derived from the Rayleigh-Love model and one-dimensional viscoelastic model. According to the Laplace transform method and the relationships among parameters of the model, the solutions to complex impedance at the bottom of the drill string are obtained, and then the comparison results are analyzed, which is the lateral inertia effect on longitudinal vibration characteristics. The researches show that the smaller the length of the drill string, the greater the cross-sectional area of the drill string, the greater the damping coefficient of bottom hole on the bottom of the drill string, and the more evident the effect on the dynamic stiffness of the drill string with lateral inertia effect. The Poisson ratio of the drill string only has some effects on it taking account of the lateral inertia effect, and the influence is relatively small compared with the former three conditions.
\end{abstract}

\section{Introduction}

In oil and gas drilling engineering, the drill string is a slender structure connecting downhole tools and drilling rig. Its dynamic performance is one of the key factors affecting the drilling efficiency and cost. Also, the results caused by drill string vibration features include rock-breaking performance of drill bit, drilling ROP (rate of penetration), wellbore quality, and downhole tools fatigues [1-4]. According to drilling condition, the drill string vibration can be divided into three forms such as longitudinal, lateral, and torsional vibration, in which the longitudinal vibration is the main factor of drilling efficiency and safety. The longitudinal vibration makes the drill bit move up and down, which results in the constant change of ROP, the service life of drill bit cutting element, or drilling footage [5-7]. To itself, longitudinal vibration may cause the drill string fatigue fracture [8].

For the solutions of drill string vibration analysis methods with complex influence factors and boundary conditions, the related researches include taking the drill string as elastomer, or obtaining vibration equations with dynamics FEM (finite element method), or analyzing longitudinal vibration considering the coupling effects of wellbore friction or the hydrodynamic interaction of drilling fluid [9-14]. However, in light of the drilling actual condition and well structure, as an elongated rod, the lateral inertia has an important influence on the longitudinal vibration of drill string. In fact, the drill longitudinal string vibration characteristics cannot be fully reflected with ignoring the lateral inertia effect [15]. Moreover, with the search results of reference articles, previous research work was not found about the lateral inertia effect on drill string longitudinal vibration. Based on this, the influence of the lateral inertia effect on the drill string longitudinal vibration is discussed in this paper. According to well structure and drill string working conditions, the longitudinal vibration models whether considering the lateral inertia or not are established. Moreover, the solution method of drill string key parameter impedance at the bottomhole is obtained.

With the presented analysis models and solution equations, the influences of considering the lateral inertia effect or not on drill string longitudinal vibration are discussed. 


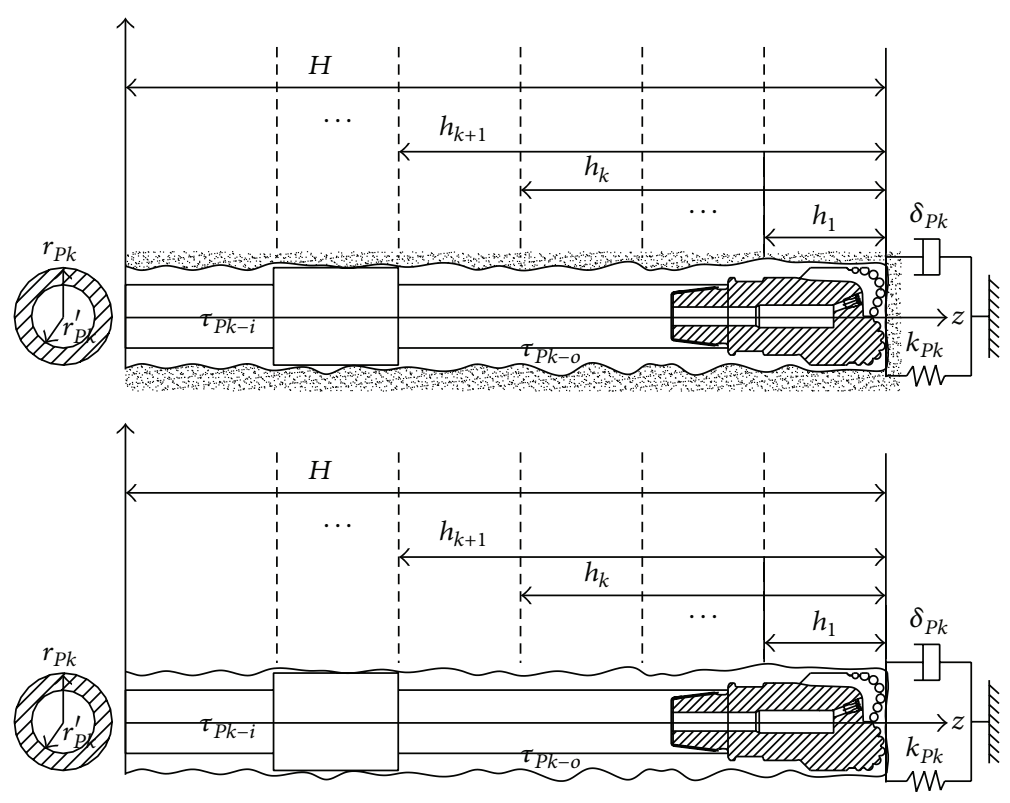

FIGURE 1: Longitudinal vibration model of drill string.

Meanwhile, by comparing different calculation results, some key parameters' influences on vibration features are presented, such as the drill string length, inside and outside radius, damping coefficient, and Poisson's ratio. The research method and model can provide reference for drill string vibration research. At the same time, the research results can also present theoretical and actual value for optimization of downhole tools design and safety evaluation of drilling operations.

\section{Analysis Method and Mathematical Model}

Based on the real condition of the drill string, related assumptions are proposed to simplify the research for drill string longitudinal vibration [16]. The following assumptions are made: the cross-sectional surface of the drill string is equivalently circular; the drill string axis coincides with borehole axis; the drilling fluid is regarded as viscoelastic layer which can be divided into several layers; and the drilling fluids inside and outside drill string have identical characteristics; the vibration velocity of drill string is much larger than the flow rate of drilling fluid.

According to drilling condition, the drill string vibration analysis model is presented as in Figure 1 wherein $h_{k}$ denotes the location layer of $k$ th drill string, $H$ is the total length of the drill string, $r_{P k}$ and $r_{P k}^{\prime}$, respectively, denote the outer and inner radius of $k$ th drill string, $\tau_{P k-i}, \tau_{P k-o}$, respectively, denote the shear stress of drilling fluid inside and outside $k$ th drill string, $k_{P k}$ is the stiffness coefficient, and $\delta_{P k}$ means the damping coefficient of the $k$ th drill string. Usually, in the absence of inner and outer mud pressure, this vibration reduces to the classical wave vibration for longitudinal waves in a uniform rod.

2.1. Model of Drill String without Lateral Inertia Effect. The deformation produced in a uniform drill string while it vibrates in a borehole is symmetric about its axis. For establishing the longitudinal vibration model of drill string without lateral inertia effect, regarding the drill string as a one-dimensional sticky elastomer and by using the laws of mass and momentum conservation, the vibration equation of the $k$ th drill string segment can be obtained as

$$
\begin{aligned}
& E_{P k} A_{k} \frac{\partial^{2} w_{k}}{\partial z^{2}}-2 \pi \tau_{P k-o} r_{P k}-2 \pi \tau_{P k-i} r_{P k}^{\prime}=\rho_{P k} A_{k} \frac{\partial^{2} w_{k}}{\partial t^{2}} \\
&\left(v_{f}>v_{v}, v_{f}>0\right), \rho^{\prime} \\
& E_{P k} A_{k} \frac{\partial^{2} w_{k}}{\partial z^{2}}+2 \pi \tau_{P k-o} r_{P k}-2 \pi \tau_{P k-i} r_{P k}=\rho_{P k} A_{k} \frac{\partial^{2} w_{k}}{\partial t^{2}} \\
&\left(v_{f}\right.\left.<v_{v}, v_{f}>0\right), \\
& E_{P k} A_{k} \frac{\partial^{2} w_{k}}{\partial z^{2}}+2 \pi \tau_{P k-o} r_{P k}+2 \pi \tau_{P k-i} r_{P k}^{\prime}=\rho_{P k} A_{k} \frac{\partial^{2} w_{k}}{\partial t^{2}} \\
&\left(v_{f}>v_{v},\right.\left.v_{f}<0\right), \\
& E_{P k} A_{k} \frac{\partial^{2} w_{k}}{\partial z^{2}}-2 \pi \tau_{P k-o} r_{P k}+2 \pi \tau_{P k-i} r_{P k}^{\prime}=\rho_{P k} A_{k} \frac{\partial^{2} w_{k}}{\partial t^{2}} \\
&\left(v_{f}<v_{v}, v_{f}<0\right),
\end{aligned}
$$

wherein the right-hand side of this equation denotes the mud pressures, which is substituted with axial displacements. The left-hand side of it denotes inertia force and the shear stress of drilling fluid inside and outside the drill string. $w_{k}$ denotes the longitudinal displacement of the $k$ th drill string segment, which is function of time $t$ and coordinate $z ; w_{k}=w_{k}(z, t)$. $v_{v}, v_{f}$ represent the vibration velocity of drill string and the flow rate of drilling fluid, respectively. Moreover, $E_{P k}$ denotes the elastic modulus of the $k$ th drill string segment, $\rho_{P k}$ is 
the density, $A_{k}$ represents the cross-sectional area of $k$ th drill string segment, and the expression is given by

$$
A_{k}=\pi\left(r_{P k}^{2}-r_{P k}^{\prime 2}\right) \text {. }
$$

According to the real working condition of the drilling, the relationship between $v_{v}$ and $v_{f}$ is $v_{f} \ll v_{v}$ and the movement of the drill string is always to the right. So the calculation formula should be denoted as

$$
\begin{gathered}
E_{P k} A_{k} \frac{\partial^{2} w_{k}}{\partial z^{2}}+2 \pi \tau_{P k-o} r_{P k}-2 \pi \tau_{P k-i} r_{P k}^{\prime} \\
=\rho_{P k} A_{k} \frac{\partial^{2} w_{k}}{\partial t^{2}} .
\end{gathered}
$$

To the shear stress of drilling fluid inside and outside $k$ th drill string, $\tau_{P k-i}, \tau_{P k-o}$, the expressions can be written as

$$
\begin{gathered}
\tau_{P k-i}=K_{k-i} w_{k}(z, t), \\
\tau_{P k-o}=K_{k-o} w_{k}(z, t),
\end{gathered}
$$

where $K_{k-i}, K_{k-o}$ are the longitudinal shear stiffness of drilling fluid at the position of inside and outside $k$ th drill string segment. With applied Laplace transform of (1) and consistent with the assumption conditions, the following equation can be obtained:

$$
\begin{aligned}
E_{P k} A_{k} & \frac{\partial^{2} W_{k}}{\partial z^{2}} \\
- & {\left[\rho_{P k} A_{k} s^{2}-2 \pi K_{k-o} r_{P k}+2 \pi K_{k-i} r_{P k}^{\prime}\right] W_{k}=0, }
\end{aligned}
$$

in which the Laplace transform with respect to time of $w_{k}=$ $w_{k}(z, t)$ is represented by $W_{k}=W_{k}(z, s)$, and the transform relation is

$$
W_{k}(z, s)=L\left[w_{k}(z, t)\right]=\int_{0}^{+\infty} w_{k}(z, t) e^{-s t} d t .
$$

The definition of symbol $\alpha$ is as follows:

$$
\alpha=\sqrt{\frac{\rho_{P k} A_{k} s^{2}-2 \pi\left(K_{k-o} r_{P k}-K_{k-i} r_{P k}^{\prime}\right)}{E_{P k} A_{k}}} .
$$

Then, the general solution of $W_{k}(z, s)$ can be gained as the following form:

$$
W_{k}(z, s)=C_{k} e^{\alpha z}+D_{k} e^{-\alpha z},
$$

where $C_{k}, D_{k}$ denote undetermined coefficients determined by boundary conditions, respectively.

During oil and gas field drilling process, the vibration of drill bit is caused partly because of the uneven bottomhole. Assuming that the force of bottomhole to the drill bit is $f_{k}(z, t)$, according to the transitivity of force, the force on the bottom of the drill string can be also denoted as $f_{k}(z, t)$. So the bottom and top of the drill string can be described as

$$
\begin{aligned}
\left.E_{P k} A_{k} \frac{\partial W_{k}(z, s)}{\partial z}\right|_{z=0} & =f_{k}(z, s), \\
\left.E_{P k} \frac{\partial W_{k}(z, s)}{\partial z}\right|_{z=H} & =-\left.\left(k_{P k}+\delta_{P k} s\right) W_{k}(z, s)\right|_{z=H},
\end{aligned}
$$

where the Laplace transform with respect to time of $f_{k}(z, t)$ is represented by $f_{k}(z, s)$. Furthermore, with (8) and (9) substituted into (5), the following equations can be obtained:

$$
\begin{aligned}
C_{k}-D_{k} & =\frac{f_{k}(z, s)}{\alpha E_{P k} A_{k}} \\
C_{k} & =\frac{E_{P k} \alpha-\left(k_{P k}+\delta_{P k} s\right)}{E_{P k} \alpha+\left(k_{P k}+\delta_{P k} s\right)} e^{-2 \alpha H} D_{k} .
\end{aligned}
$$

Here, defining the symbol $\gamma$, its expression is given by

$$
\gamma=\frac{E_{P k} \alpha-\left(k_{P k}+\delta_{P k} s\right)}{E_{P k} \alpha+\left(k_{P k}+\delta_{P k} s\right)} e^{-2 \alpha H} .
$$

Then, taking the results of $C_{k}, D_{k}$ and definition of $\gamma$ into (7), the displacement of the drill string $W_{k}(z, s)$ can be obtained as follows:

$$
W_{k}(z, s)=\frac{f_{k}(z, s)}{(\gamma-1) \alpha E_{P k} A_{k}}\left(\gamma e^{\alpha z}+e^{-\alpha z}\right) .
$$

Moreover, assume that

$$
s=i \omega
$$

Then, the Laplace transform is equivalent to the unilateral Fourier transform, so the response of displacement frequency can be expressed as $W_{k}(z, i w)$. The complex impedance of the drill string is derived as follows:

$$
K_{P d}=\frac{\alpha A_{k}(\gamma-1) E_{P k}}{\gamma+1} .
$$

The complex impedance of the drill string bottom is equal to the complex stiffness, which can be expressed in the plural form as follows:

$$
K_{P d}=K_{r}+i C_{i}
$$

in which the plural real component $K_{r}$ denotes the real dynamic stiffness, which reflects the drill string ability of longitudinal deformation resistance. In other words, when the drill string is pressed by the vibration force, the value of the dynamic stiffness has close association with the deformation of the drill string. On the other hand, the imaginary component $C_{i}$ denotes the dynamic damping, which reflects the drill string energy dissipation.

2.2. Model of Considering Lateral Inertia Effect. Considering the influence of lateral inertia effect on drill string vibration characteristics with actual situation, the vibration of the $k$ th 
drill string segment can be described by the theory of Rayleigh-Love rod as follows:

$$
\begin{gathered}
E_{P k} A_{k} \frac{\partial^{2} w_{k}}{\partial z^{2}}-2 \pi\left(\tau_{P k-i} r_{P k}+\tau_{P k-o} r_{P k}^{\prime}\right) \\
=\rho_{P k} A_{k}\left(\frac{\partial^{2} w_{k}}{\partial t^{2}}-v_{P k}^{2}\left(r_{P k}^{2}-r_{P k}^{\prime 2}\right) \frac{\partial^{4} w_{k}}{\partial z^{2} \partial t^{2}}\right) \\
\quad\left(v_{f}>v_{v}, v_{f}>0\right), \\
E_{P k} A_{k} \frac{\partial^{2} w_{k}}{\partial z^{2}}+2 \pi\left(\tau_{P k-i} r_{P k}-\tau_{P k-o} r_{P k}^{\prime}\right) \\
=\rho_{P k} A_{k}\left(\frac{\partial^{2} w_{k}}{\partial t^{2}}-v_{P k}^{2}\left(r_{P k}^{2}-r_{P k}^{\prime 2}\right) \frac{\partial^{4} w_{k}}{\partial z^{2} \partial t^{2}}\right) \\
E_{P k} A_{k} \frac{\partial^{2} w_{k}}{\partial z^{2}}+2 \pi\left(\tau_{P k-i} r_{P k}+\tau_{P k-o} r_{P k}^{\prime}\right) \\
=\rho_{P k} A_{k}\left(\frac{\partial^{2} w_{k}}{\partial t^{2}}-v_{P k}^{2}\left(r_{P k}^{2}-r_{P k}^{\prime 2}\right) \frac{\partial^{4} w_{k}}{\partial z^{2} \partial t^{2}}\right) \\
E_{P k} A_{k} \frac{\partial^{2} w_{k}}{\partial z^{2}}-2 \pi\left(\tau_{P k-i} r_{P k}-\tau_{P k-o} r_{P k}^{\prime}\right) \\
\left(\frac{\partial^{2} w_{k}}{\partial t^{2}}-v_{P k}^{2}\left(r_{P k}^{2}-r_{P k}^{\prime 2}\right) \frac{\partial^{4} w_{k}}{\partial z^{2} \partial t^{2}}\right)
\end{gathered}
$$

where $v_{P k}$ denotes Poisson's ratio of the $k$ th drill string segment. It is also worth noticing that both coupling terms are proportional to Poisson's ratio. This is reasonable since this ratio describes the radial contraction of a rod subjected to axial strain. According to the drilling field situation, the analysis condition can be obtained as $v_{f}-v_{v} \ll 0$ and $v_{f}>0$, and the above equation with (16) can be simplified to

$$
\begin{aligned}
& E_{P k} A_{k} \frac{\partial^{2} w_{k}}{\partial z^{2}}+2 \pi\left(\tau_{P k-i} r_{P k}-\tau_{P k-o} r_{P k}^{\prime}\right) \\
& =\rho_{P k} A_{k}\left(\frac{\partial^{2} w_{k}}{\partial t^{2}}-v_{P k}^{2}\left(r_{P k}^{2}-r_{P k}^{\prime 2}\right) \frac{\partial^{4} w_{k}}{\partial z^{2} \partial t^{2}}\right) .
\end{aligned}
$$

For obtaining the results of the equation, similar to the method which is used for the solution of model without considering the influence of lateral inertia effect on drill string vibration, considering the initial and continuity conditions, the vibration equation of the drill string is solved by Laplace transform, and the displacement expression of the drill string, with considering the influence of lateral inertia effect, can be obtained.
Here defining symbols $\alpha, \beta$, and $\gamma$, their expressions are given as

$$
\begin{aligned}
& \alpha=\sqrt{\frac{\rho_{P k} A_{k} s^{2}-2 \pi\left(K_{k-o} r_{P k}-K_{k-i} r_{P k}^{\prime}\right)}{E_{P k} A_{k}+\rho_{P k} A_{k} \nu_{P k}^{2}\left(r_{P k}^{2}-r_{P k}^{\prime 2}\right) s^{2}}}, \\
& \beta=\rho_{P k} \nu_{P k}^{2}\left(r_{P k}^{2}-r_{P k}^{\prime 2}\right) s^{2} \\
& \gamma=\frac{\left(E_{P k}+\beta\right) \alpha-\left(k_{P k}+\delta_{P k} s\right)}{\left(E_{P k}+\beta\right) \alpha+\left(k_{P k}+\delta_{P k} s\right)} e^{-2 \alpha H} .
\end{aligned}
$$

Then, the displacement expression of the drill string can be obtained as

$$
W_{k}(z, s)=\frac{f_{k}(z, s)}{(\gamma-1) \alpha\left(E_{P k} A_{k}+A_{k} \beta\right)}\left(\gamma e^{\alpha z}+e^{-\alpha z}\right) .
$$

Moreover, the analytical solution of the complex impedance at the bottomhole of drill string can be expressed as

$$
K_{P d}=\frac{\alpha A_{k}(\gamma-1)\left(E_{P k}+\beta\right)}{\gamma+1} .
$$

\section{Numerical Example and Analysis of Key Parameters Influence}

For contrastively analyzing the influence of design parameters on the characteristics of drill string longitudinal vibration, the complex impedance results are discussed by using the analysis models established above, including the models with and without lateral inertia effect. In the calculation results figures, the horizontal axis is the vibration frequency, and the longitudinal axis is the dynamic stiffness at the bottom of drill string. First of all, the material parameters of the drill string and drilling fluid, including the density, elastic modulus, stiffness coefficient, and longitudinal shear stiffness, are shown in Table 1.

3.1. The Drill String Length. The length of the drill string is also on behalf of the well depth. At the same time, to the ratio of drill string length and diameter, the bigger ratio is corresponding to the poorer vibration stability of drill string. The influence of drill string length on its dynamic stiffness at the bottom is analyzed as in Figure 2, including taking account of the lateral inertia effect or not. The numerical example parameters are shown in Table 2, including the drill string Poisson's ratio, length, radius, and damping coefficient, and the drill string length value includes $1800 \mathrm{~m}$ and $2000 \mathrm{~m}$.

In Figure 2, the symbol $H$ denotes the length of drill string model without considering the lateral inertia effect, $\mathrm{m}$. The symbol $h$ denotes the length of drill string with considering the lateral inertia effect, $\mathrm{m}$. The results of drill string dynamic stiffness are presented corresponding to frequency of $20 \mathrm{~Hz}$ to $30 \mathrm{~Hz}$, including different drill string length and models of considering the lateral inertia effect or not. The following conclusions can be obtained: with the increasing of frequency, the amplitude of drill string dynamic stiffness presents increasing trend, including the results of different length and 
TABLE 1: Material parameters of the drilling string.

\begin{tabular}{lc}
\hline Parameters name & Results \\
\hline Density of drill string $\rho_{P k}\left(\mathrm{~kg} / \mathrm{m}^{3}\right)$ & 8000.00 \\
Elastic modulus of drill string $E_{P k}(\mathrm{MPa})$ & $2.06 \times 10^{3}$ \\
Stiffness coefficient $k_{P k}(\mathrm{~N} / \mathrm{m})$ & $1.00 \times 10^{5}$ \\
Longitudinal shear stiffness of drilling fluid inside drill string $K_{k-i}(\mathrm{Mpa} / \mathrm{m})$ & 0.3 \\
Longitudinal shear stiffness of drilling fluid outside drill string $K_{k-o}(\mathrm{Mpa} / \mathrm{m})$ & 0.1 \\
\hline
\end{tabular}

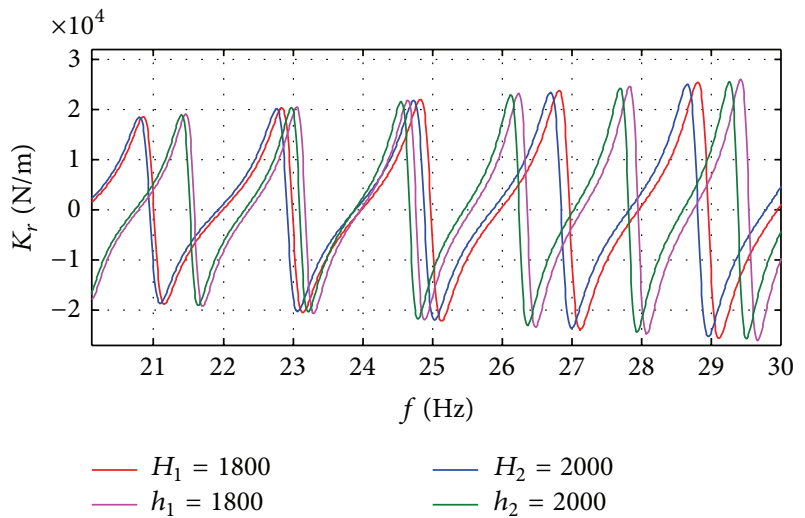

FIGURE 2: Influence of the drill string length on dynamic stiffness.

TABLE 2: Calculation parameters of the length of drill string influence.

\begin{tabular}{lc}
\hline Name of parameters & Results \\
\hline Poisson's ratio of the drill string $v$ & 0.30 \\
Length of the drill string $H_{1}, h_{1}(\mathrm{~m})$ & 1800 \\
Length of the drill string $H_{2}, h_{2}(\mathrm{~m})$ & 2000 \\
Outside radius of the drill string $r_{P k}(\mathrm{~m})$ & 0.10 \\
Inside radius of the drill string $r_{P k}^{\prime}(\mathrm{m})$ & 0.08 \\
Damping coefficient $\delta_{P k}(\mathrm{Ns} / \mathrm{m})$ & 10000 \\
\hline
\end{tabular}

analysis models. Meanwhile, to the lateral inertia effect, the influence on drill string dynamic stiffness can be almost negligible when the frequency is low or zero. However, with the increasing of frequency, such that the frequency is greater than $25 \mathrm{~Hz}$, the influence of lateral inertia effect becomes more obvious. To the results of models considering lateral inertia effect or not, in the increasing period of dynamic stiffness, the absolute value of considering lateral inertia effect is greater than that of ignoring lateral inertia effect. To the results of drill string different lengths, the influence of lateral inertia effect is bigger when the drill string is shorter.

3.2. The Inside and Outside Radius. The inside and outside radius of drill string are determined by the size specification. The influence of radius change on the dynamic stiffness is analyzed as in Figure 3, including the models of considering the lateral inertia effect or not. As before, the numerical example parameters are shown in Table 3, including the drill string different inside and outside radius value.

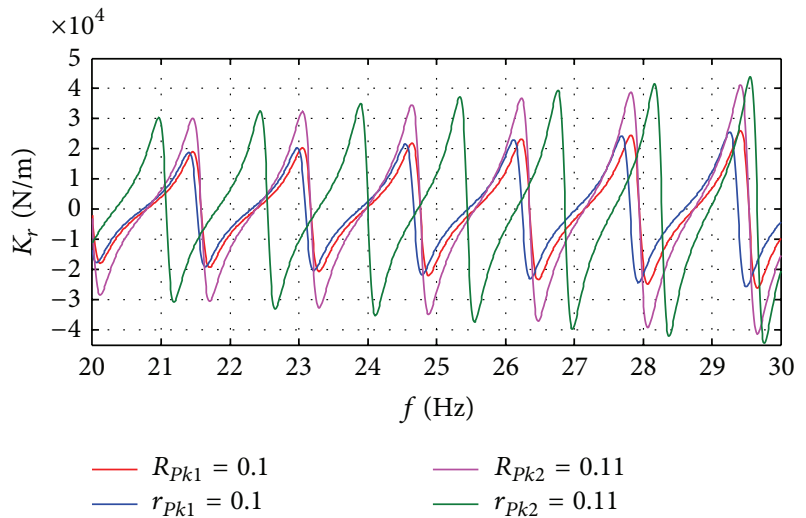

FIGURE 3: Influence of outside radius on dynamic stiffness.

TABLE 3: Calculated parameters of the inside and outside radius influence.

\begin{tabular}{lc}
\hline Name of parameters & Results \\
\hline Poisson's ratio of the drill string $\nu$ & 0.30 \\
Length of the drill string $H(\mathrm{~m})$ & 2000 \\
Outside radii of the drill string $R_{P k 1}, r_{P k 1}(\mathrm{~m})$ & 0.10 \\
Outside radii of the drill string $R_{P k 2}, r_{P k 2}(\mathrm{~m})$ & 0.11 \\
Inside radii of the drill string $R_{P k 1}^{\prime}, r_{P k 1}(\mathrm{~m})$ & 0.08 \\
Inside radii of the drill string $R_{P k 2}^{\prime}, r_{P k 2}(\mathrm{~m})$ & 0.09 \\
Damping coefficient $\delta_{P k}(\mathrm{Ns} / \mathrm{m})$ & 10000 \\
\hline
\end{tabular}

In Figures 3 and 4 , the symbols $R_{P k}$ and $R_{P k 1}$ denote the radius of drill string model without considering the lateral inertia effect, $\mathrm{m}$. The symbols $r_{P k}$ and $r_{P k}^{\prime}$ denote the radius of drill string model considering the lateral inertia effect, $\mathrm{m}$. The results of drill string dynamic stiffness are presented corresponding to frequency of $20 \mathrm{~Hz}$ to $30 \mathrm{~Hz}$, as shown in Figures 3 and 4, including different inside and outside radius and models with lateral inertia effect or not. As before, the following conclusions can be got: with the frequency increasing, the dynamic stiffness amplitude presents increasing trend. Meanwhile, when outside radius increases or inside radius reduces, equivalent to the area increasing, the increasing trend of the dynamic stiffness becomes more notable. Also, to the results of models with lateral inertia effect or not, in the increasing period of dynamic stiffness, the value of model with lateral inertia effect is greater than that without lateral inertia effect. Meanwhile, with bigger difference between the drill string outside and inside radius, the lateral inertia effect has a more important influence on the dynamic stiffness of drill string. 


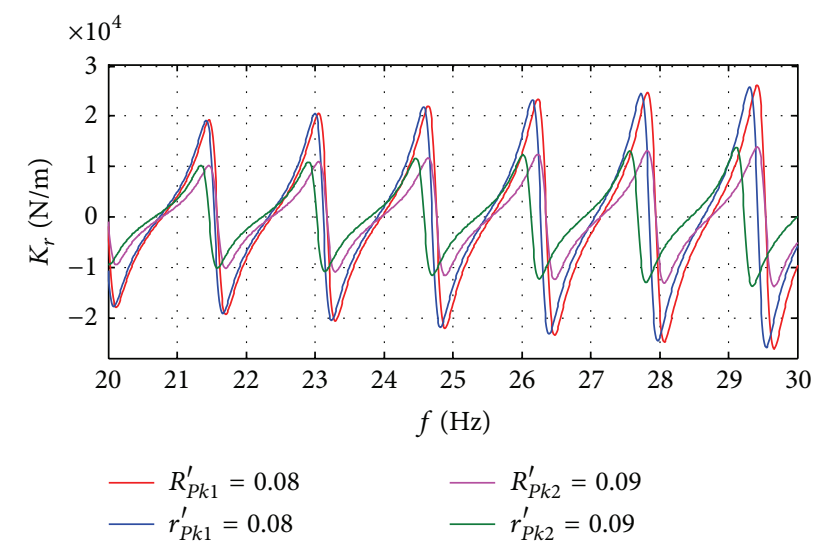

FIGURE 4: Influence of inside radius on dynamic stiffness.

TABLE 4: Calculation parameters of the damping coefficient influence.

\begin{tabular}{lc}
\hline Name of parameters & Results \\
\hline Poisson's ratio of the drill string $\nu$ & 0.30 \\
Length of the drill string $H(\mathrm{~m})$ & 2000 \\
Outside radius of the drill string $r_{P k}(\mathrm{~m})$ & 0.10 \\
Inside radius of the drill string $r_{P k}^{\prime}(\mathrm{m})$ & 0.08 \\
Damping coefficients $\delta_{P k 1}^{\prime}, \delta_{P k 1}(\mathrm{Ns} / \mathrm{m})$ & 8000 \\
Damping coefficients $\delta_{P k 2}^{\prime}, \delta_{P k 2}(\mathrm{Ns} / \mathrm{m})$ & 10000 \\
\hline
\end{tabular}

3.3. The Damping Coefficient. The damping coefficient of the bottomhole to drill string is influential to the drill string longitudinal vibration, and the lateral inertia effect is directly related to the damping coefficient. According to the drilling field conditions, the calculation parameters analyzing damping coefficient are shown in Table 4, taking the damping coefficient as 8000 and $10000 \mathrm{Ns} / \mathrm{m}$.

In Figure 5, the symbol $\delta_{P k}$ denotes the damping coefficient of model without lateral inertia effect, $\mathrm{Ns} / \mathrm{m}$. The symbol $\delta_{P k}^{\prime}$ denotes the damping coefficient of model considering lateral inertia effect, Ns $/ \mathrm{m}$. Figure 5 shows the influence of the damping coefficient on the drill string dynamic stiffness corresponding to frequency of $30 \mathrm{~Hz}$ to $40 \mathrm{~Hz}$. It can be observed that the increasing trend of the dynamic stiffness becomes more notable when the damping coefficient decreased and the cyclic frequency increased, including models with lateral inertia effect or not. In a single cycle, when it is closer to the crest or trough, the difference of drill string dynamic stiffness is bigger. When considering the lateral inertia effect, the absolute value of dynamic stiffness in increasing period is bigger than that of the model without lateral inertia effect. However, the bigger damping coefficient does not mean more obvious influence in the drill string dynamic stiffness, which indicates that the damping of bottomhole to drill string can weaken the influence of lateral inertia effect on the dynamic stiffness.

3.4. Poisson's Ratio. Poisson's ratio is the lateral deformation coefficient of material, which reflects the lateral deformation elastic constants of material. In the static force condition,

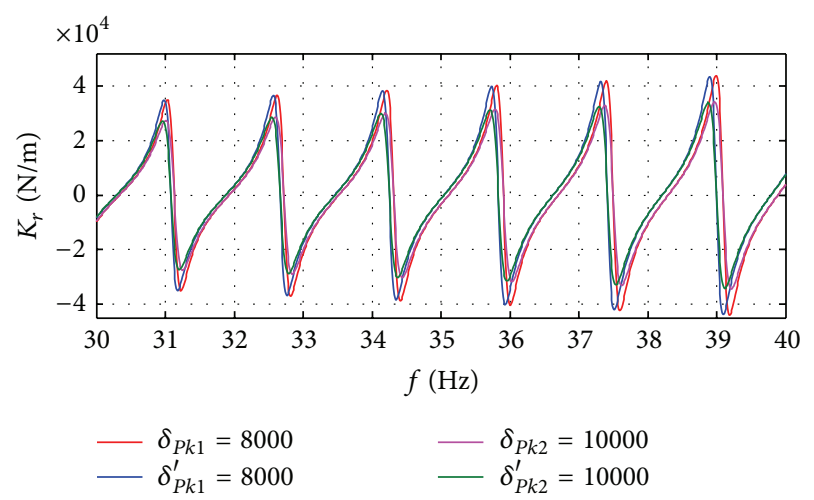

Figure 5: Influence of the damping coefficient on dynamic stiffness.
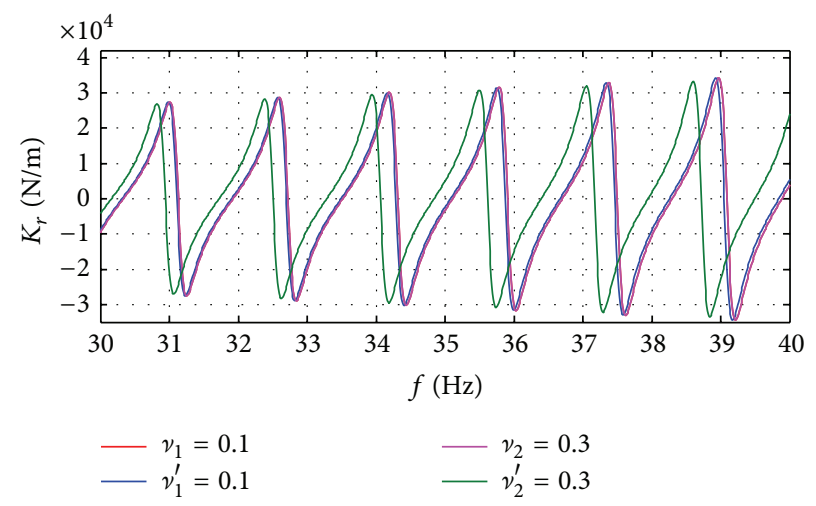

Figure 6: Influence of Poisson's ratio on dynamic stiffness.

TABLE 5: Calculated parameters of Poisson's ratio influence.

\begin{tabular}{lc}
\hline Name of parameters & Results \\
\hline Poisson's ratios of the drill string $v_{1}^{\prime}, v_{1}$ & 0.10 \\
Poisson's ratios of the drill string $v_{2}^{\prime}, v_{2}$ & 0.30 \\
Length of the drill string $H(\mathrm{~m})$ & 2000 \\
Outside radius of the drill string $r_{P k}(\mathrm{~m})$ & 0.10 \\
Inside radius of the drill string $r_{P k}^{\prime}(\mathrm{m})$ & 0.08 \\
Damping coefficient $\delta_{P k}(\mathrm{Ns} / \mathrm{m})$ & 10000 \\
\hline
\end{tabular}

Poisson's ratio change of drill string is very small, and it is generally taken as $v=0.25$. However, in the dynamic load case, the dynamic Poisson's ratio is commonly taken as $v=$ $0.1 \sim 0.3$. According to the analysis above, the calculated parameters analyzing Poisson's ratio are shown in Table 5, taking Poisson's ratio as 0.10 and 0.30 .

In Figure 6, the symbol $v$ denotes Poisson's ratio of model without lateral inertia effect. On the other hand, the symbol $v^{\prime}$ denotes Poisson's ratio of model considering lateral inertia effect. Figure 6 shows the influence of Poisson's ratio on the drill string dynamic stiffness in the frequency of $30 \mathrm{~Hz}$ to $40 \mathrm{~Hz}$. It can be seen that the increasing trend of the drill string dynamic stiffness becomes more obvious when Poisson's ratio and cyclic frequency increase, both of the models with lateral inertia effect or not. 
TABLE 6: The free vibration natural frequency in different conditions.

\begin{tabular}{lcc}
\hline Boundary conditions & Without lateral inertia & Lateral inertia \\
\hline The first-order natural frequency $(\mathrm{rad} / \mathrm{s})$ & 0.03 & 0.04 \\
The second-order natural frequency $(\mathrm{rad} / \mathrm{s})$ & 0.05 & 0.06 \\
The third-order natural frequency $(\mathrm{rad} / \mathrm{s})$ & 0.07 & 0.09 \\
\hline
\end{tabular}

However, different from other parameters results, the change of the drill string Poisson's ratio has influence on the results of model considering lateral inertia effect, while it has no influence on the results of model without considering lateral inertia effect, which indicates that the lateral inertia effect includes the effect of Poisson's ratio. Meanwhile, when considering the lateral inertia effect, the absolute value of dynamic stiffness is increasing with the drill string Poisson's ratio in the increasing period.

3.5. Natural Frequency. Assume that the length of the drill string is $3500 \mathrm{~m}$, and the boundary conditions are prescribed by the above, as well as the structure parameters of the drill string. The longitudinal vibration model of the drill string is analyzed with different conditions. The first three-order natural frequencies of the drill string longitudinal vibration are shown in Table 6 whether considering the lateral inertia effect or not.

The calculation results illustrate that the natural frequency increases with the increase of frequency order. And when there is no inertia, it is less than the situation with lateral inertia effect. When considering the inertia effect, the vibration is coupled with the longitudinal vibration, which will cause the vibration difference. According to adjusting the drilling parameters, the drill string resonance can be avoided and make drilling optimization possible.

\section{Conclusion}

According to the drilling field conditions, the analysis model of drill string longitudinal vibration is established with the lateral inertia effect, and the Laplace transform is used for the complex impedance solution of drill string bottom. By using the established equations and analyzing the results of numerical examples, the influence of design parameters on drill string dynamic stiffness is discussed, including the results of models considering the lateral inertia effect or not. Within the frequency range of drilling field conditions, these conclusions can be drawn:

(1) The cyclical transformation amplitude of drill string dynamic stiffness, whether considering the radial inertia effect or not, presents increasing with frequency and the length of the drill string. Therefore, for resisting drill string longitudinal deformation and excessive vibration, the appropriate length of drill string should be considered in the well structure design.

(2) For the drill string dynamic stiffness increasing with the cross-sectional area, combining the relationship of sectional area and inside and outside radius, the influence of sectional area on drill string dynamic stiffness can provide reference for the design of BHA (Bottomhole Assembly).

(3) With the damping coefficient increasing, the amplitude of drill string dynamic stiffness is reducing, which would lead to the vibration force increasing. The results are coinciding with the drilling actual condition. Moreover, the consequences can provide basic data for the design of downhole friction reduction tools.

(4) To the influence of Poisson's ratio on drill string dynamic stiffness, the results are some difference comparing with other parameters. Based on the model without considering the lateral inertia effect, the change of Poisson's ratio has no influence on the results of drill string dynamic stiffness. However, to the model including the lateral inertia effect, the influence of Poisson's ratio on drill string dynamic stiffness cannot be ignored. According to the drilling field condition, the results are important for drilling dynamics analysis, especially in deep and ultradeep drilling or some new wells, which is the basis for improving the rock-breaking efficiency and ROP.

\section{Conflict of Interests}

The authors declare that there is no conflict of interests regarding the publication of this paper.

\section{Acknowledgments}

This work is supported by Open Fund (OGE201403-05) of Key Laboratory of Oil \& Gas Equipment, Ministry of Education (Southwest Petroleum University), National Natural Science Foundation of China (no. 51074202 and no. 11102173), Major Cultivation Foundation of Sichuan Education Department (12ZZ003, no. 667), and Graduate Student Innovation Fund of Southwest Petroleum University (CX2015SY06).

\section{References}

[1] J. J. Bailey and I. Finnie, "An analytical study of drill-string vibration," Journal of Engineering for Industry, vol. 82, no. 2, pp. 122-127, 1960.

[2] S. A. Al-Hiddabi, B. Samanta, and A. Seibi, "Non-linear control of torsional and bending vibrations of oilwell drillstrings," Journal of Sound and Vibration, vol. 265, no. 2, pp. 401-415, 2003.

[3] Q. Xue, R. Wang, F. Sun, and Z. Huang, "Chaotic vibration analysis of the bottom rotating drill string," Shock and Vibration, vol. 2014, Article ID 429164, 8 pages, 2014. 
[4] H. Hakimi and S. Moradi, "Drillstring vibration analysis using differential quadrature method," Journal of Petroleum Science and Engineering, vol. 70, no. 3-4, pp. 235-242, 2010.

[5] W. Wang, Q. Hu, H. Liu, and W. Zhang, "Analysis on longitudinal vibration of drill string and the corresponding application," Journal of Vibration and Shock, vol. 6, pp. 229-233, 2011.

[6] J. Li, T. Yan, X. Sun, and S. Peng, "Finite element analysis on drilling string axial vibration in a crooked hole," in Proceedings of the International Conference on Pipelines and Trenchless Technology (ICPTT '12), vol. 10, pp. 1328-1334, Wuhan, China, October 2012.

[7] T. Yan, X. Wang, S. Li, X. Bi, and C. Han, "Finite element analysis of longitudinal and lateral coupled vibration of drillstring," Oil Field Equipment, vol. 3, p. 12, 2012.

[8] X. Yan, J. Sun, M. Zhang et al., "Analysis of longitudinal vibration of drill strings using equivalent network," Oil Field Equipment, vol. 4, p. 5, 2010.

[9] S. M. Sahebkar, M. R. Ghazavi, S. E. Khadem, and M. H. Ghayesh, "Nonlinear vibration analysis of an axially moving drillstring system with time dependent axial load and axial velocity in inclined well," Mechanism and Machine Theory, vol. 46, no. 5, pp. 743-760, 2011.

[10] W. B. Wu, K. H. Wang, D. H. Wu, and B. N. Ma, "Study of dynamic longitudinal impedance of tapered pile considering lateral inertial effect," Chinese Journal of Rock Mechanics and Engineering, vol. 30, no. 2, pp. 3618-3625, 2011.

[11] T. Ding and C. Li, "Analysis of coupling axial vibrations between drilling fluids and drillstring," Chinese Journal of Mechanical Engineering, vol. 43, no. 9, pp. 215-219, 2007.

[12] V. I. Gulyayev and O. I. Borshch, "Free vibrations of drill strings in hyper deep vertical bore-wells," Journal of Petroleum Science and Engineering, vol. 78, no. 3-4, pp. 759-764, 2011.

[13] C. Bu, X. Li, L. Sun, and B. Xia, "Arithmetic solution for the axial vibration of drill string coupling with a down-the-hole hammer in rock drilling," Journal of Vibration and Control, 2014.

[14] Y. A. Khulief, F. A. Al-Sulaiman, and S. Bashmal, "Vibration analysis of drillstrings with self-excited stick-slip oscillations," Journal of Sound and Vibration, vol. 299, no. 3, pp. 540-558, 2007.

[15] W.-L. Wang, Q.-A. Hu, H.-W. Liu, and W. Zhang, "Analysis on longitudinal vibration of drill string and the corresponding application," Journal of Vibration and Shock, vol. 30, no. 6, pp. 229-233, 2011.

[16] A. A. Jafari, R. Kazemi, and M. F. Mahyari, "The effects of drilling mud and weight bit on stability and vibration of a drill string," Journal of Vibration and Acoustics, Transactions of the ASME, vol. 134, no. 1, Article ID 011014, 2012. 


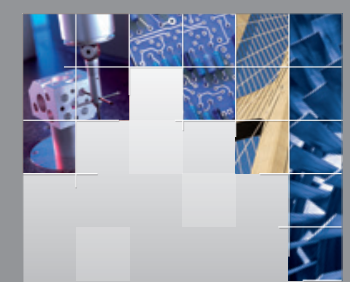

\section{Enfincering}
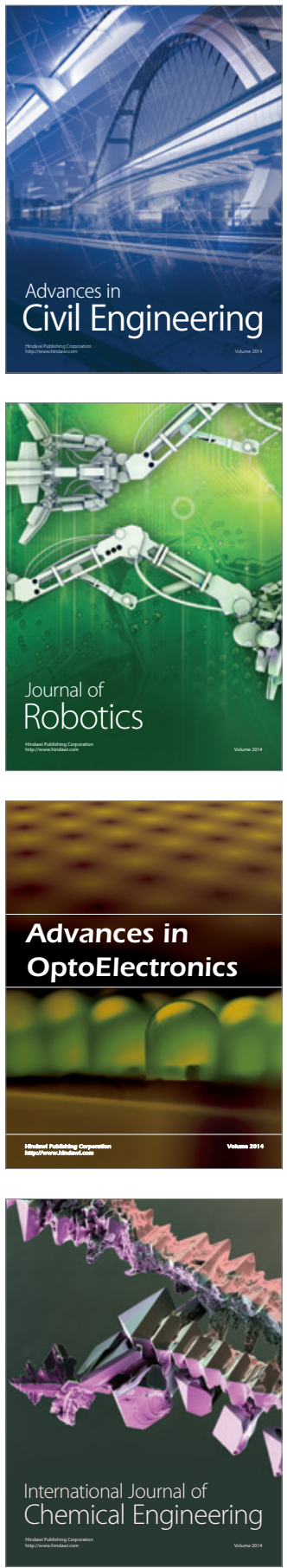

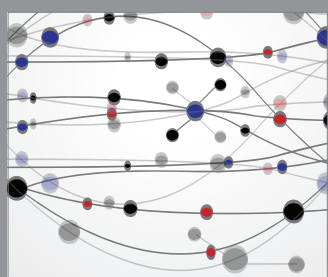

The Scientific World Journal

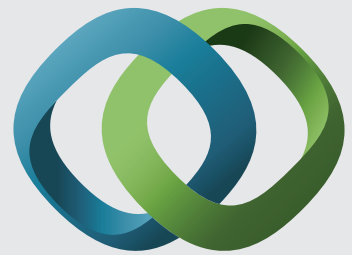

\section{Hindawi}

Submit your manuscripts at

http://www.hindawi.com
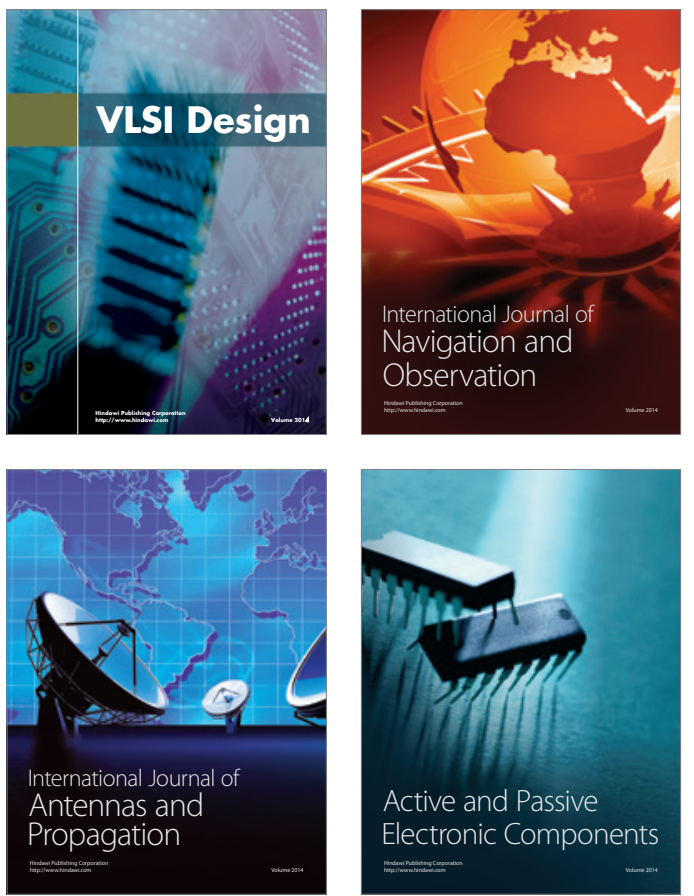
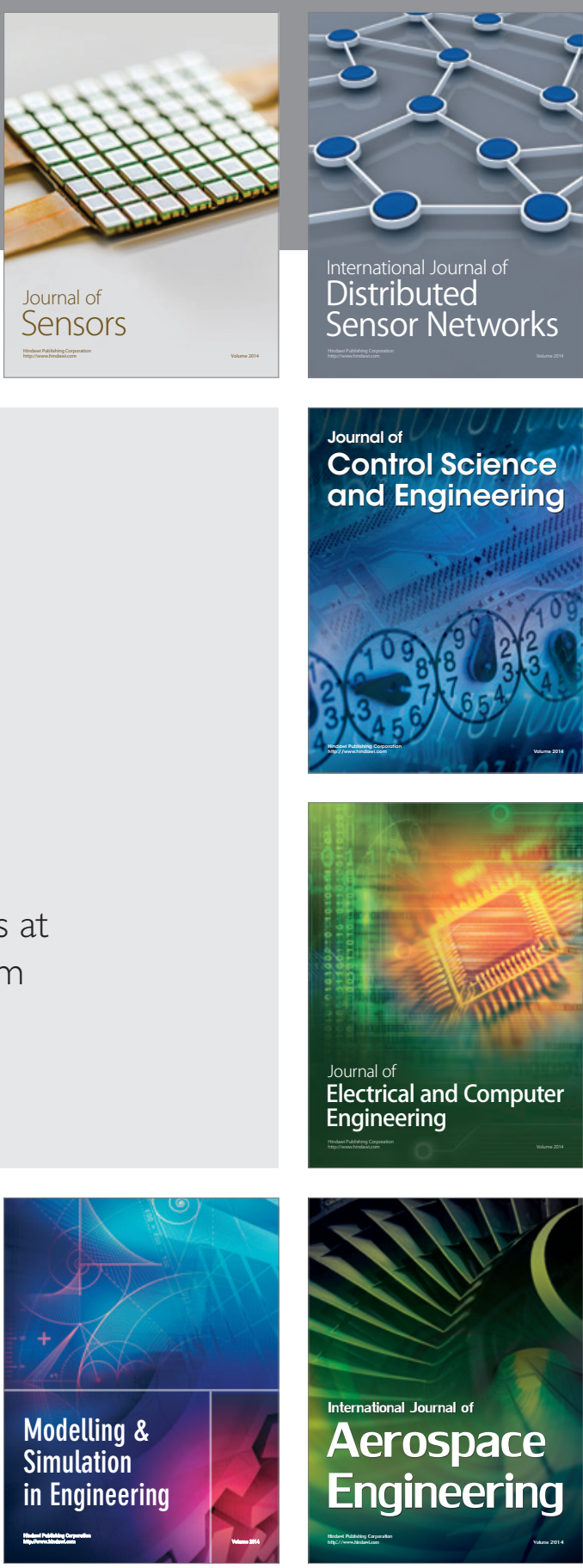

International Journal of

Distributed

Sensor Networks

Journal of

Control Science

and Engineering
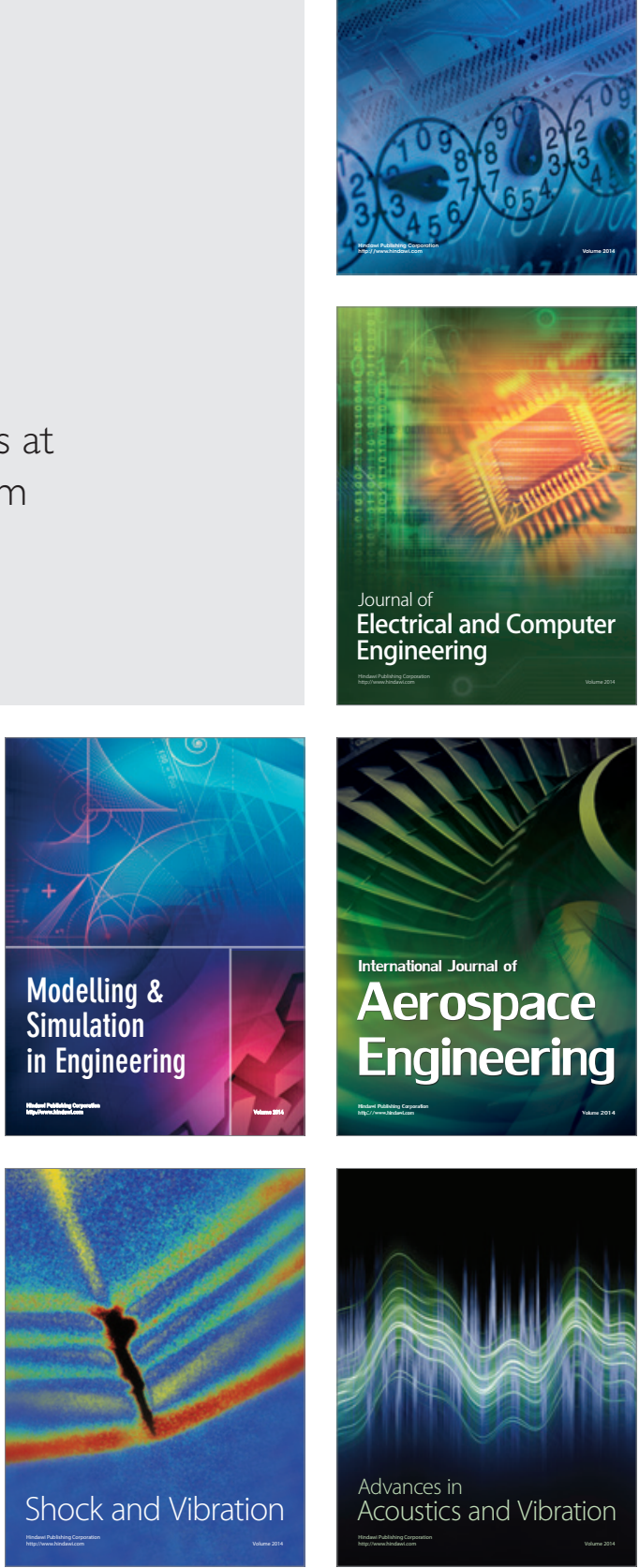